\title{
Growth hormone response to apomorphine in panic disorder: comparison with major depression and normal controls
}

\begin{abstract}
Several lines of evidence suggest that dopamine might be involved in anxiety states. In the present study we assessed the growth hormone $(\mathrm{GH})$ response to $0.5 \mathrm{mg}$ apomorphine (a dopaminergic agonist) in 10 male drug-free inpatients meeting Research Diagnostic Criteria for panic disorder who were compared with 10 male major depressive inpatients and 10 male normal controls. The three groups differed significantly in the GH peak response (mean $\pm \mathrm{SD}$ ): $27.8 \pm 12.5 \mathrm{ng} / \mathrm{ml}$ in panics, $5.4 \pm$ $4.0 \mathrm{ng} / \mathrm{ml}$ in major depressives, and $25.8 \pm 11.3 \mathrm{ng} / \mathrm{ml}$ in normal controls $(F(2,27)=15.3 ; P=0.00003)$. Although there were significant differences between panics and major depressives ( $P=0.00004)$, and between major depressives and controls $(P=0.00004)$, panics did not significantly differ from controls. These results do not support the hypothesis of an overlap between panic and affective disorders, and suggest that the hypothalamo-GH-somatomedin axis could be intact in panic disorder.
\end{abstract}

Key words Panic disorder - Depression - Dopamine

\section{Introduction}

Current hypothesis about the etiopathology of panic disorder (PD) principally involve serotonergic, noradrenergic, and benzodiazepine systems (Pecknold and Luthe 1990; Charney et al. 1990; Nutt et al. 1990). A large body of data also suggests a role for the dopaminergic system as a possible etiological factor in PD. Indeed, Stein et al. (1990) showed a higher incidence of panic attacks in patients with Parkinson's disease. Roy-Byrne et al. (1985 a) reported indirect biological support for increased dopaminergic functioning in $\mathrm{PD}$ patients by demonstrating a blunted thyrotropin-stimulating hormone (TSH) and pro-

William Pitchot (『) - Michel Hansenne

Antonio Gonzalez Moreno - Marc Ansseau Psychiatric Unit, University Hospital of Liège, B-4000 Liège, Belgium lactin (PRL) response to thyrotropin-releasing hormone (TRH). Recently, we reported a significantly higher growth hormone $(\mathrm{GH})$ response to apomorphine, a dopaminergic agonist, in PD patients compared with minor and major depressives suggesting an increased dopamine receptor sensitivity in PD (Pitchot et al. 1992). Moreover, this study did not support the hypothesis of a common link between panic and affective disorders. However, the lack of a normal control group represented a major methodological problem. In the present study we compare PD patients to major depressives and normal controls.

\section{Subjects and methods}

Ten male inpatients (mean age 36.7 years; SD 10.2 years) meeting Research Diagnostic Criteria (RDC) for panic disorder without major depression were admitted to the Psychiatric Unit of the University Hospital of Liège, Belgium. All patients had a score less than 12 on the 17-item Hamilton Depression Scale (Hamilton 1960). The PD patients were compared with 10 male major-depressive inpatients (mean age 36.6 years; SD 9.2 years) according to RDC with a score of 25.6 (SD 5.3) on the 17-item Hamilton Depression Scale, and 10 male normal controls (mean age 25.4 years; SD 7.9 years). There was no significant difference in mean weight between the three groups. All patients were free of medical illness and assessed after a drug-free period of at least 2 weeks. Patients with a basal systolic blood pressure less than $100 \mathrm{mmHg}$ were excluded from the study. Moreover, to be included patients had to present basal GH level less than $5 \mathrm{ng} / \mathrm{ml}$ before the neuroendocrine test. The exclusion of subjects with a basal GH value greater than $5 \mathrm{ng} / \mathrm{ml}$ was recommended by Laakmann (1990) who demonstrated that "prestimulator" healthy volunteers responded significantly less to a noradrenergic challenge than healthy volunteers with low basal values. Finally, all patients were fully informed of the study and gave their consent.

The apomorphine test was performed in all subjects at bedrest after an overnight fast. At 7 A.M. an indwelling catheter was inserted into a forearm vein. Blood samples of $10 \mathrm{ml}$ were collected at $-20,0,20,40,60$, and 120 min after injection at 8 A.M. of 0.5 $\mathrm{mg}$ apomorphine diluted in saline to obtain $0.5 \mathrm{ml}$ subcutaneously.

The GH was measured with a double antibody radioimmunoassay (Franchimont 1968), with intraassay and interassay coefficients of variation of $13.3 \pm 4.7 \%$ and $14.8 \pm 9.6 \%$, respectively, and a detection limit of $0.2 \mathrm{ng} / \mathrm{ml}$. The $\mathrm{GH}$ responses to apomorphine were assessed by $\mathrm{GH}$ peak values following injection. The analysis was performed using absolute GH values as well as dif- 
ferences related to basal ( 0 ) levels (relative values). Because the correlations between absolute and relative values were very high $(r>0.98)$, only the absolute values are reported here. The responses of the patients were compared using a single analysis of variance (ANOVA) with posthoc analyses. Moreover, in order to control the possible influence of some outliers on the positive findings, the comparison was also performed by means of the Wilcoxon nonparametric test.

\section{Results}

All patients exhibited baseline $\mathrm{GH}$ values below $3 \mathrm{ng} / \mathrm{ml}$. The three groups differed significantly in the GH peak response (mean $\pm \mathrm{SD}$ ): $27.8 \pm 12.5 \mathrm{ng} / \mathrm{ml}$ in panics, $5.4 \pm$ $4.0 \mathrm{ng} / \mathrm{ml}$ in major depressives, and $25.8 \pm 11.3 \mathrm{ng} / \mathrm{ml}$ in normal controls $(\mathrm{F}(2,27)=15.3 ; P=0.00003)$; (Figure 1) While there were significant differences between panics and major depressives $(\mathrm{F}(1,18)=28.9 ; P=0.00004)$, and between major depressives and controls $(F(1,18)=28.8$; $P=0.00004)$, panics did not significantly differ from controls $(\mathrm{F}(1,18)=0.13$; n.s.). The analysis using the Wilcoxon nonparametric test confirmed that there were significant differences between panics and major depressives ( $z=-3.36 ; P<0.001$ ), and between major depressives and controls $(z=3.6 ; P<0.001)$, but panics did not significantly differ from controls $(z=-0.4 ; P=0.67)$.

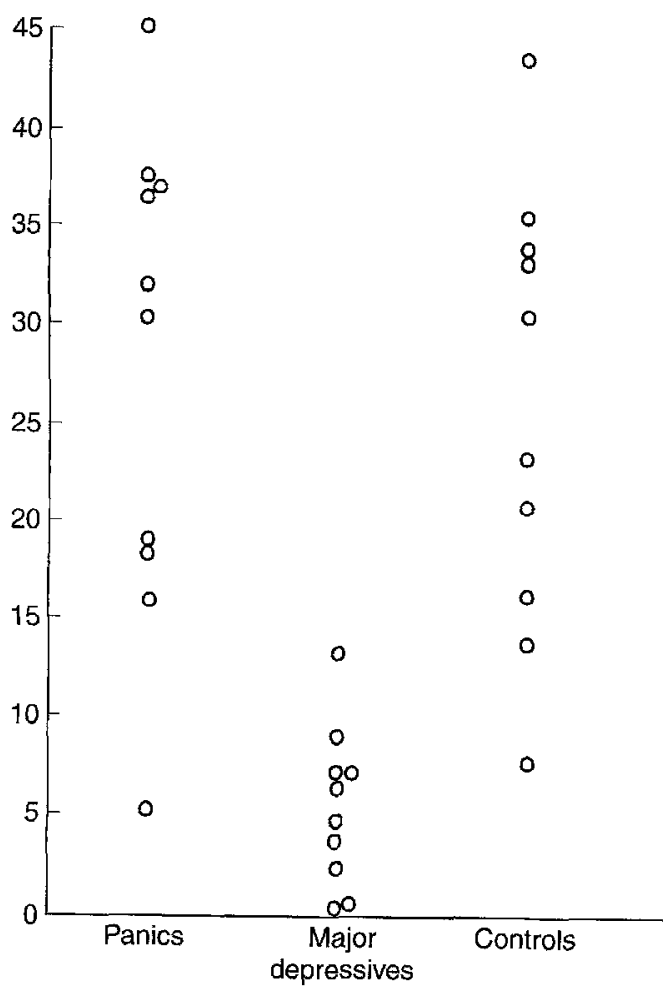

Fig. 1 Distribution of growth hormone peak values after apomorphine in 10 panics, 10 major depressives, and 10 normal controls

\section{Discussion}

The results of the present study show that there is no overlap between panic and affective disorders in relation to GH response to apomorphine, which is in line with previous studies assessing other biological parameters, such as sleep architecture (Akiskal et al. 1984), platelet imipramine binding (Pecknold and Luthe 1990), TSH responses to TRH (Stein and Uhde 1991), and dexamethasone suppression test (Roy-Byrne et al. 1985 b) which were found to differentiate panic and depressed patients. Moreover, the present study does not provide evidence of a dopaminergic overactivity in panic disorder. In 1986 Roy-Byrne et al. did not find any significant difference in the plasmatic concentrations of the dopamine metabolite homovanillic acid (HVA) between PD patients and controls. However, higher plasma HVA concentrations were found in a subgroup of PD patients characterized by a higher level of anxiety and a greater number of panic attacks in the past year. In fact, dopamine seems to be implicated in the control of anxiety symptoms, but does not play a major role as an etiological factor in panic disorder. In contrast, Gurguis et al. (1991) found lower plasma HVA levels suggesting decreased dopaminergic function in PD patients; however, this finding could be related to concomitant depression.

The major finding of this study is that PD patients present normal GH responses to apomorphine, which contrasts with several studies reporting blunted responses across different probes (clonidine, yohimbine, caffeine, glucose, GHRH). On the basis of these last observations, Uhde et al. (1992) raised the possibility that panic disorder might be a condition characterized by an intrinsic abnormality in the hypothalamic-GH-somatomedin axis. The results of the current study suggest that the axis could be intact in PD patients. Moreover, our data provide evidence that the blunted $\mathrm{GH}$ response to clonidine observed in panic disorder suggests an $\alpha 2$-receptor-based abnormality in panic disorder, rather than a global alteration in $\mathrm{GH}$ function.

A major pitfall of this study is the possible inadequacy of the drug-free wash-out period of 2 weeks, which could be insufficient. Indeed, tricyclic antidepressants are known to impair the $\mathrm{GH}$ response to clonidine for periods longer than 3 weeks following their discontinuation (Schittecatte et al. 1989) and could influence $\mathrm{GH}$ response to apomorphine. However, recently we assessed the $\mathrm{GH}$ response to apomorphine in 11 male DSM-III-R major depressive inpatients who had never received antidepressant therapy compared with 11 normal controls and 11 major depressive inpatients drug-free for at least 2 weeks, and demonstrated that a wash-out period of 2 weeks could be sufficient in studies assessing the $\mathrm{GH}$ response to apomorphine (Pitchot et al. 1995).

In conclusion, these results suggest that the $\mathrm{GH}$ response to apomorphine is able to differentiate panic and depressed patients. Moreover, the hypothesis of a dopaminergic hyperactivity in panic disorder is not supported by 
the results of the present study. Our data also suggest that the hypothalamic-GH-somatomedin axis is intact in panic disorder. However, our sample is small, and therefore these results should be taken with caution.

\section{References}

Akiskal HS, Lemmi H, Dickson H, King D, Yerevanian B, Van Valkenburg C (1984) Chronic depressions. Part 2. Sleep EEG differentiation of primary dysthymic disorders from anxious depressions. J Affect Disord 6:287-295

Charney DS, Woods SW, Price LH, Goodman WK, Glazer WM, Heninger GR (1990) Noradrenergic dysregulation in panic disorder. In Ballenger JC (ed) Neurobiology of panic disorder. Alan R. Liss, New York, pp 91-105

Gurguis GNM, Mefford IN, Uhde TW (1991) Hypothalamic-pituitary-adrenocortical activity in panic disorder: relationship to plasma catecholamine metabolites. Biol Psychiatry 30:502506

Hamilton M (1960) A rating scale for depression. J Neurol Neurosurg Psychiatry $23: 56-62$

Nutt DJ, Glue P, Lawson C (1990) The neurochemistry of anxiety: an update. Prog Neuropsychopharmacol Biol Psychiatry 14: $737-752$

Pecknold JC, Luthe L (1990) Sleep studies and neurochemical correlates in panic disorder and agoraphobia. Prog Neuropsychopharmacol Biol Psychiatry 14:753-758

Pitchot W, Ansseau M, Gonzalez Moreno A, Hansenne M, von Frenckell R (1992) Dopaminergic function in panic disorder: comparison with major and minor depression. Biol Psychiatry 32: 1004-1011
Pitchot W, Gonzalez Moreno A, Hansenne M, Ansseau M (1995) Effect of antidepressant therapy on the growth hormone response to apomorphine. Neuropsychobiology (in press)

Roy-Byme PP, Uhde TW, Gold PW, Rubinow DR, Post RM (1985 a) Neuroendocrine abnormalities in panic disorder. Psychopharmacol Bull 3:550-554

Roy-Byrne PP, Bierer LM, Uhde TW (1985b) The dexamethasone suppression test in panic disorder: comparison with normal controls. Biol Psychiatry 20:1237-1240

Roy-Byrne PP, Uhde TW, Sack DA, Linnoila M, Post RM (1986) Plasma HVA and anxiety in patients with panic disorder. Biol Psychiatry $21: 847-849$

Schittecatte M, Charles G, Machowski R, Wilmotte J (1989) Tricyclic wash-out and growth hormone response to clonidine. Br J Psychiatry 154:858-863

Stein MB, Heuser IJ, Juncos JL, Uhde TW (1990) Anxiety disorders in patients with Parkinson's disease. Am I Psychiatry 147: $217-220$

Stein MB, Uhde TW (1991) Endocrine, cardiovascular, and behavioral effects of intravenous protirelin in patients with panic disorder. Arch Gen Psychiatry 48:148-155

Uhde TW, Tancer ME, Rubinow DR, Roscow DB, Boulenger JP, Vittone B, Gurguis G, Geraci M, Black B, Post RM (1992) Evidence for hypothalamo-growth hormone dysfunction in panic disorder; profile of growth hormone $(\mathrm{GH})$ responses to clonidine, yohimbine, caffeine, glucose, GRF and TRH in panic disorder patients versus healthy volunteers. Neuropsychopharmacology $6: 101-118$ 